\title{
Experimental and Simulation Analysis of Natural Gas-Diesel Combustion in Dual-Fuel Engines
}

\author{
Pavlos Dimitriou ${ }^{1}$, Taku Tsujimura ${ }^{1 *}$, Hirokazu Kojima ${ }^{1}$, Kenji Aoyagi $^{2}$, Naoki Kurimoto $^{2}$ and \\ Yoshiaki Nishijima ${ }^{3}$ \\ ${ }^{1}$ National Institute of Advanced Industrial Science and Technology (AIST), Renewable Energy Research Center, Koriyama, Japan, \\ ${ }^{2}$ DENSO CORPORATION, Kariya, Japan, ${ }^{3}$ Aichi Institute of Technology, Toyota, Japan
}

\section{OPEN ACCESS}

Edited by:

Masahiro Shioji,

Kyoto University, Japan

Reviewed by:

Amin Paykani,

University of Hertfordshire,

United Kingdom

Khanh Duc Cung,

Southwest Research Institute (SwRI),

United States

*Correspondence:

Taku Tsujimura

Tsujimura-taku@aist.go.jp

Specialty section:

This article was submitted to

Engine and Automotive Engineering,

a section of the journal

Frontiers in Mechanical Engineering

Received: 18 March 2020 Accepted: 22 September 2020

Published: 21 October 2020

Citation:

Dimitriou P, Tsujimura T, Kojima $\mathrm{H}$, Aoyagi $K$, Kurimoto $N$ and Nishijima $Y$ (2020) Experimental and Simulation

Analysis of Natural Gas-Diesel

Combustion in Dual-Fuel Engines.

Front. Mech. Eng. 6:543808.

doi: 10.3389/fmech.2020.543808
The recent strict emission regulations and the necessity to reduce the global $\mathrm{CO}_{2}$ levels have promoted research studies in alternative fuel combustion technologies. Dual-fuel technology is a fascinating approach as it can combine the benefits of two fuels to achieve high thermal efficiency and lower harmful emissions. Natural gas burns cleaner than other fossil fuels, and its recent low price makes it an attractive fuel as a near-term solution. The utilization of natural gas with diesel in a compression ignition engine can result in efficiency improvement and lower $\mathrm{CO}_{2}$ emissions. However, at low engine loads, natural gas-diesel operation suffers from low combustion efficiency and high unburned hydrocarbon and carbon monoxide emissions. The present paper collates the work of experimental and simulation studies on natural gas-diesel dual-fuel operation over three different engine setups. Two single-cylinder, with and without optical access, and a multi-cylinder engine were used to analyze the effects of different diesel injection and air-path strategies on the combustion performance, with a focus on the low-load operation zone. The results show that the injection timing, as well as intake charge dilution, can severely promote clean combustion at the low-load zone. An advanced diesel injection can enhance the dieselnatural gas homogeneity within the cylinder and improve the combustion efficiency of the engine. On the other hand, high levels of exhaust gas recirculation are mandatory to suppress the NOx formation and further enhance the engine's brake thermal efficiency.

Keywords: natural gas, diesel, dual-fuel, engine combustion, simulation

\section{INTRODUCTION}

The compression ignition (CI) engine, also known as the diesel engine, has been a vital workhorse of the global energy industry for more than a hundred years. However, with the world currently facing an escalating environmental crisis and with government policies designed to promote clean energy solutions, the role of the $\mathrm{CI}$ engine in the coming sustainable energy economy is ambiguous.

The aspirational target of Paris agreement to limit greenhouse gas emissions by at least $40 \%$ by 2030 (UNFCC, 2015) will necessitate CI engines operating with low-polluting fuels. The dual-fuel operation of a CI engine with renewable eco-friendly fuels such as hydrogen (Dimitriou and Tsujimura, 2017) and ammonia (Dimitriou and Javaid, 2020) can contribute to significant, often higher than the target, $\mathrm{CO}_{2}$ emission reductions. However, today around $95 \%$ of the world's hydrogen production is generated from non-renewable sources such as natural gas and coal, and only $5 \%$ is generated by water electrolysis (IRENA, 2019). 
As a shorter-term solution, the use of compressed natural gas (CNG) as the primary fuel of a CI engine has received significant interest since it can produce lower specific $\mathrm{CO}_{2}$ emissions than other petroleum-derived fuels. The recent low natural gas prices combined with the simple modifications required for the existing CI engines to operate on gas make it an attractive solution. However, the high autoignition limit of the gas prevents its combustion by compression (Sahoo et al., 2009), unless it is co-combusted with a lower autoignition fuel such as diesel.

In this combustion mode, the natural gas is supplied to the intake manifold or close to the intake ports leading to a homogeneous in-cylinder charge. The uniform natural gas-air mixture provides premixed combustion characteristics, which is triggered by the diffusion combustion of diesel fuel (Wei and Geng, 2016). Natural gas-diesel dual-fuel engines exhibit higher thermal efficiency than spark-ignition $\mathrm{CNG}$ engines over the entire engine load range (Kojima et al., 2016). Compared to the conventional diesel fuel operation, natural gas dual-fuel engines can yield significant $\mathrm{CO}_{2}$ benefits as methane, which is CNG's primary component, has one of the lowest carbon contents among hydrocarbons. The $\mathrm{CO}_{2}$ reductions can be enlarged at higher loads due to the engine's ability to run at higher natural gas energy share ratios (Lounici et al., 2014).

The effect of the natural gas on the NOx formation of the dualfuel engine is highly dependent on the operating conditions and the diesel amount. At lower engine loads, the NOx formation of a dual-duel engine can be lower than that of a conventional engine. The reduction could be due to a lower in-cylinder temperature as a result of the higher specific heat capacity of natural gas than that of the air, and a longer ignition delay, which often leads to lower combustion efficiencies (Wei and Geng, 2016). At higher engine loads, the NOx deterioration is often a result of an intense heat release in the premixed combustion zone, followed by a higher pressure rise rate (Selim, 2001) and in-cylinder temperatures.

Natural gas can also provide significant reductions in soot formation due to it free of aromatics and sulfur composition (Maricq et al., 2002), and the fact that it promotes premixed combustion with lower diffusion flames (Liu et al., 2013). On the other hand, significant carbon monoxide (CO) and hydrocarbons (HC) emission penalties, due to a high amount of unburned methane, have been reported in the literature (Shenghua et al., 2003; Cheenkachorn et al., 2013; Liu et al., 2013).

Furthermore, the main challenge of the dual-fuel engine is the poor performance at low-load conditions. Previous studies (Karim, 2003; Paul et al., 2013) have shown that at low equivalence ratios, high carbon monoxide, and unburned hydrocarbon emissions are formed under high CNG-to-diesel energy share ratios. This increase in emissions results from a deteriorated combustion efficiency due to the incapacity of diesel fuel to ignite the lean natural gas-air mixture (Tsujimura et al., 2012), inducing bad and slow combustion (Lounici et al., 2014). Papagiannakis et al. (2010) reported a decrease of up to $50 \%$ on the brake thermal efficiency (BTE) of a dual-fuel engine compared to the conventional diesel operation. Abdelaal and Hegab (2012) could only achieve higher BTE for the dual-fuel engine at high load conditions with the maximum increase being in the level of $3 \%$ at $95 \%$ of the engine's full load. The presence of a higher diesel-to-CNG ratio could resolve this issue, but it eliminates the benefits of using CNG, such as increases the $\mathrm{CO}_{2}$ emissions (Kojima et al., 2016).

Several studies have been performed in the past years to assess the optimum solutions to overcome the low combustion efficiency in the low-load zone. Liu et al. (2013) evaluated the effects of the pilot diesel quantity on the formation of unburned hydrocarbons. The authors observed a strong connection between the diesel amount and the level of $\mathrm{HC}$ with a higher diesel quantity resulting in lower HC levels. Nonetheless, their results showed that around $90 \%$ of the $\mathrm{HC}$ emission was composed of unburned methane. Yang et al. (2015) observed an improved combustion performance, such as shorter ignition delay and combustion duration, and higher BTE when the diesel pilot injection pressure raised from 46 to $72 \mathrm{MPa}$. However, despite the BTE increase, the COand total hydrocarbon (THC) emissions were increased in the high-pressure case. According to the authors, this was due to spray impingement on the piston and cylinder wall caused by the elevated injection pressure. Srinivasan et al. (2006) improved the combustion efficiency of the dual-fuel engine by advancing the start of diesel injection at about $60^{\circ} \mathrm{CA}$ before top dead center and increasing the intake gas temperature. Kusaka et al. (1998) highlighted that at low-load operation, the NO formation due to the natural gas combustion is low. The authors applied exhaust gas recirculation (EGR) and intake preheating to reduce diesel NOx and THC simultaneously while the thermal efficiency was improved.

The presents paper reports an overall approach to analyze the operation of the natural gas-diesel dual-fuel engine under different operating conditions and engine layouts. The study was conducted under different injection (i.e., pattern, timing) and airpath (i.e., EGR, boosting) strategies applied to assess the performance of the dual-fuel engine. The focus of this study is on the low-load region which is an area that suffers from low combustion efficiency. The experimental analysis presented in this paper is performed using three different engine set-ups, while the investigation is supported by computational fluid dynamics (CFD) simulations.

\section{EXPERIMENTAL APPARATUS}

In this paper, advanced experimental studies were performed under three engine set-ups presented in Table 1. Different engine layouts were used to gain a deeper understanding of the dual-fuel engine operation in single- and multi-cylinder layouts and obtaining visual access to the combustion process.

Engines set-up \#1 (Figure 1A) and set-up \#2 (Figure 1B) exhibit the same cylinder geometry characteristics with the later one featuring an optically accessible piston. As the optical engine could be operated only under cold-start conditions, a higher cetane pilot fuel, No. 0 Solvent M, was used to replace the lower cetane diesel. The third set-up (Figure 1C) is a multi-cylinder engine that was used to assess the effects of different air-path strategies on the combustion and emissions behavior of the dualfuel engine. The details about the equipment used in the three engine set-ups are analytically illustrated in Figure 1. All the 
TABLE 1 | Specifications of the three engine set-ups.

\section{Test facility}

Engine type

Bore $\times$ stroke $(\mathrm{mm})$

Displacement $\left(\mathrm{cm}^{3}\right)$

Compression ratio

Combustion chamber

Main fuel

Pilot fuel

Injection system

Nozzle type (inj. angle)

Coolant temperature

\section{Set-up \#1}

4-Stroke single-cylinder diesel engine

$92 \times 96$

638

15:1

Dish (cavity $\varphi$ : $56 \mathrm{~mm}$ )

CNG (port injection)

Diesel, CN: 56 (direct injection)

Common rail @50 MPa

$\varphi: 0.085 \mathrm{~mm} \times 12$ holes $\left(\theta: 130^{\circ}\right)$

$80 \pm 2$

\section{Set-up \#2}

4-Stroke single-cylinder diesel engine

$92 \times 96$

638

15:1

Optical

CNG (port injection)

No. 0 Solvent M, CN: 89 (direct injection)

Common rail @50 MPa

$\varphi$ : $0.085 \mathrm{~mm} \times 12$ holes $\left(\theta: 130^{\circ}\right)$

$95 \pm 2$

\section{Set-up \#3}

4-Stroke 4-cylinder diesel engine $96 \times 103$

2,981

15:1

Toroidal

CNG (port injection) Diesel, CN: 56 (direct injection)

Common rail @50 MPa

$\varphi: 0.09 \mathrm{~mm} \times 10$ holes $\left(\theta: 155^{\circ}\right)$ $80 \pm 2$

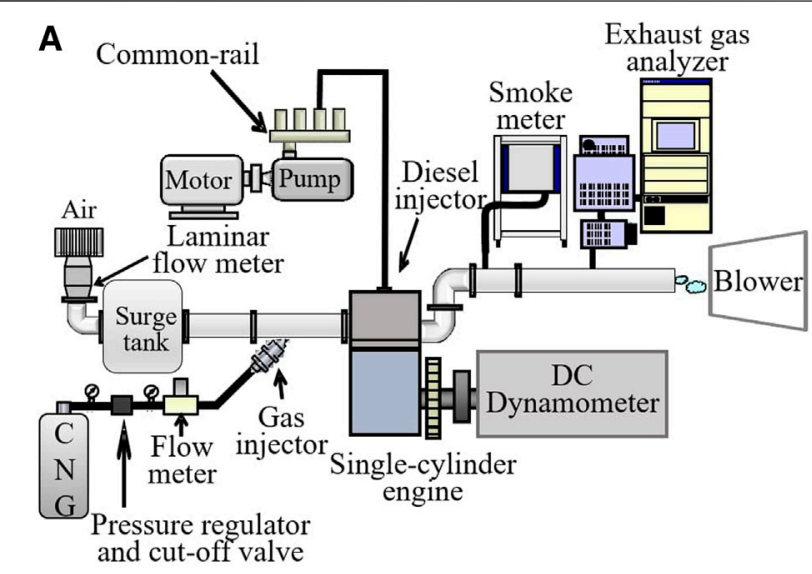

Engine Set-up \#1

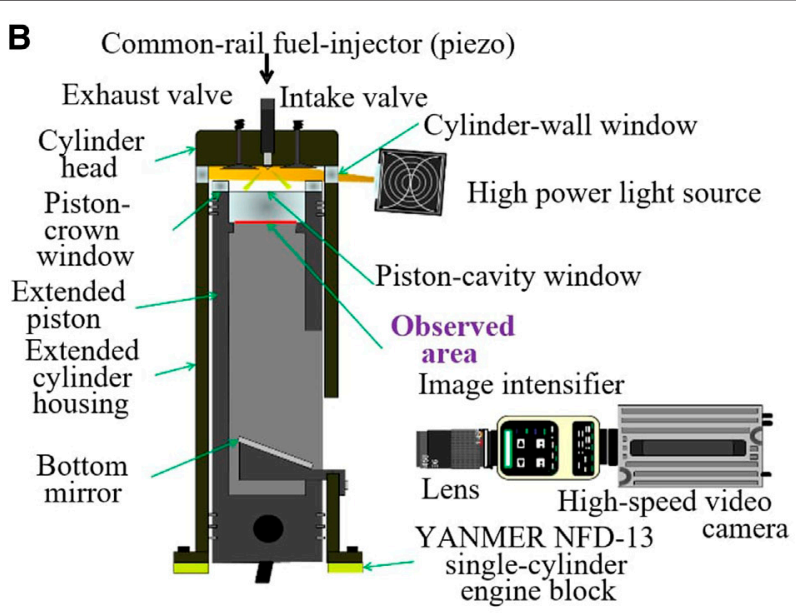

Engine Set-up \#2

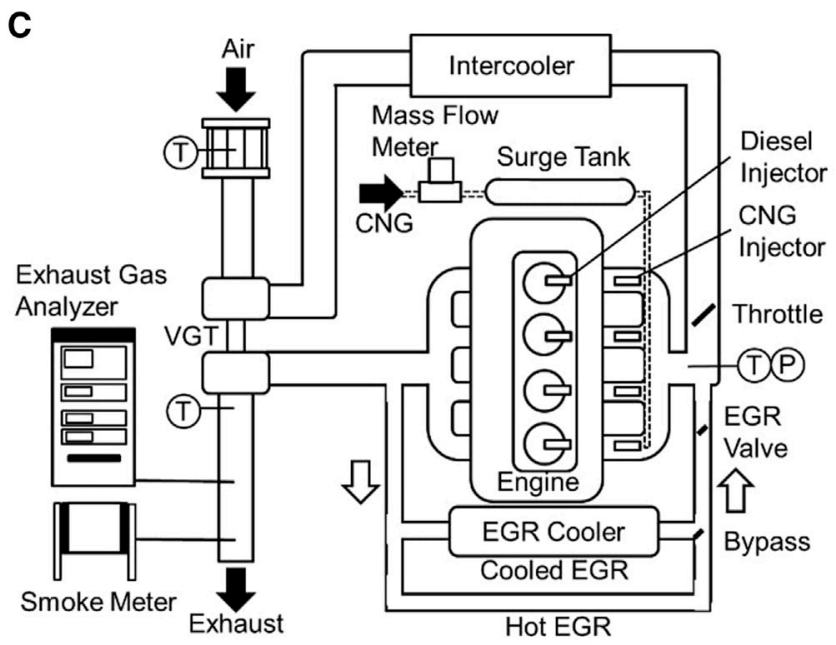

Engine Set-up \#3

FIGURE 1 | Experimental facilities: (A) set-up \#1-single-cylinder engine, (B) set-up \#2-single-cylinder with optical access, and (C) set-up \#3 multi-cylinder engine.

engine operating conditions tested in the three engine set-ups, as well as the main properties of the natural gas and liquid fuels, can be found in and 3, respectively.
For the engine set-up \# 1 and set-up \#2 with a swept volume of $638 \mathrm{~cm}^{3}$, a natural gas injector (Japan 13A grade) was placed at the intake port of the engine. The compressed gas was injected 
TABLE 2 | Engines' operating conditions.

\begin{tabular}{|c|c|c|c|}
\hline Test facility & Set-up \#1 & Set-up \#2 & Set-up \#3 \\
\hline Engine speed (rpm) & 1,200 & 1,200 & 1,200 \\
\hline $\mathrm{BMEP} /(\mathrm{IMEP})(\mathrm{MPa})$ & $(0.05-1.1)$ & $0.62 / 0.60$ & 0.3 \\
\hline CNG air excess ratio & 2.67 & 3 & 3.85 \\
\hline Diesel injection pattern & Single & Early single/split (double) & Single \\
\hline Diesel injection timing ( ${ }^{\circ} \mathrm{CA}$ ATDC) & $-3,-13,-33,-53,-63$ & $-60 /-40+T D C$ & -22.5 to -2.5 (steps of 2.5 ) \\
\hline Diesel amount (mm³/st) & $2,4,10$ & $10 / 5+5$ & 5.7 \\
\hline Boost pressure (kPa) & 100 & 100 & $100 / 120$ \\
\hline EGR rate (\%) & - & - & $0,10,20,30,50$ \\
\hline
\end{tabular}

TABLE 3 | Fuel properties.

\begin{tabular}{lccc} 
Fuel type & CNG (13A) & Diesel JIS (No. 2) & No. 0 Solvent M \\
\hline Density $\left(\mathrm{g} / \mathrm{cm}^{3}\right)$ & 0.878 & $\approx 0.832$ & 0.761 \\
$\mathrm{LHV}^{\mathrm{a}}(\mathrm{MJ} / \mathrm{kg})$ & 52.47 & 43.12 & 43.8 \\
$\mathrm{CN}^{\mathrm{b}}$ & - & 56 & 89.4 \\
Sulfur mass $(\mathrm{ppm})$ & - & $<50$ & $<1$ \\
$\mathrm{CNG}$ composition & $\mathrm{CH}_{4}: 89.6 \%, \mathrm{C}_{2} \mathrm{H}_{6}: 5.62 \%, \mathrm{C}_{3} \mathrm{H}_{8}: 3.43 \%, \mathrm{C}_{4} \mathrm{H}_{10}: 1.35 \%$
\end{tabular}

aLower heating value.

${ }^{b}$ Cetane number.

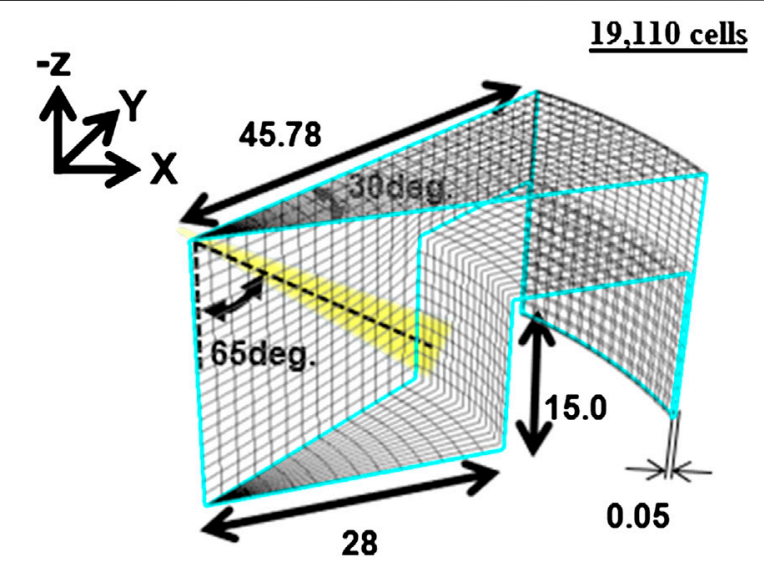

FIGURE 2 | Computational grid (30 sector mesh).

into the cylinder at $0.8 \mathrm{MPa}$ during the intake valve opening time. A 12-hole piezo-type diesel injector with a $0.085 \mathrm{~mm}$-diameter nozzle was mounted on the cylinder head. The diesel injection pressure was set at $50 \mathrm{MPa}$ for all experiments by an in-house common-rail system. The exhaust gas emission analysis was performed using the HORIBA, MEXA-7000DEGR analyzer, and the AVL 415S smoke meter. The visual access on the engine set-up \#2 was acquired by coupling a high-speed camera (FASTCAM APX RS) to an image intensifier (UVi-NAC Image Technology), as presented in Figure 1B. For the multi-cylinder engine, the CNG was supplied from a surge tank connected to the intake manifold. The gas injection period was adjusted to achieve a balanced gas flow among the cylinders, Figure 1C.

Although measurements of the exhaust smoke were taken for all three engine set-ups, it will not be reported in this paper. Since the scope of the present study is to focus on the low-load operation zone with a small diesel injection amount, the smoke levels for all cases presented were at a sufficiently low level of less than 0.10 FSN [Filter Smoke Number defined according to ISO 10054 (ISO 10054, 1998)].

\section{COMPUTATIONAL FLUID DYNAMICS SIMULATION}

Computational simulation analysis was used to obtain a better understanding of the in-cylinder combustion phenomena. For this analysis, the FORTÉ simulation package (Liang et al., 2010) linked to a chemical reaction model was used for the cylinder with a computational grid shown in Figure 2.

FORTÉ was developed from techniques used in KIVA-3V code (Amsden, 1997), and it has similar sub-models for atomization, vaporization, and interactions associated with turbulence. In this study, the Kelvin-Helmholtz Rayleigh-Taylor (KH-RT) model (Reitz and Beale, 1999) was applied to obtain an accurate prediction of the spray penetration. The KH-RT model is sensitive to the gas-drop relative velocity and mesh size. Moreover, the gas-jet model (Abani and Reitz, 2007) was also applied, aiming at mesh- and time stepindependent simulation results (Wang et al., 2010). The authors employed the turbulence interaction model proposed by Kong and Reitz (2002) to simulate the turbulence effects on combustion kinetics. The model considers that the combustion chemistry should be partly controlled by the breakup of turbulent eddies due to the imperfect mixing of fuel and oxidizer or combustion products. The local chemical time scale and turbulent scalar mixing time scale $t_{\text {mix }}$ are defined to take their interaction into consideration. Since, computational cell is not small enough to reproduce actual scales for turbulence and chemistry, the effect of turbulence of mixing on production rate of species needs to be considered. Therefore, the model requires a constant called the mixing time coefficient, $C_{t k i}$, to adjust the influence of turbulence (ANSYS, Inc., 2019).

For the dual-fuel study, a parametric analysis on the effect of the $C_{t k i}$ to the ability of the model to represent the experimental combustion data was performed. Figure 3 shows the results of the simulation model operated with $C_{t k i}$ ranging from 0 to 1 for an early fuel injection of $-60^{\circ} \mathrm{CA}$ after top dead center (ATDC). As it can be seen in the figure, the $C_{t k i}$ level has a significant effect on the hot ignition close to the top dead center (TDC) but does not significantly affect the low-temperature reaction zone at around $-20^{\circ} \mathrm{CA}$ ATDC. For this study, it was found that a $C_{t k i}$ value of 1 provides the best match between the simulated and experimental results. 


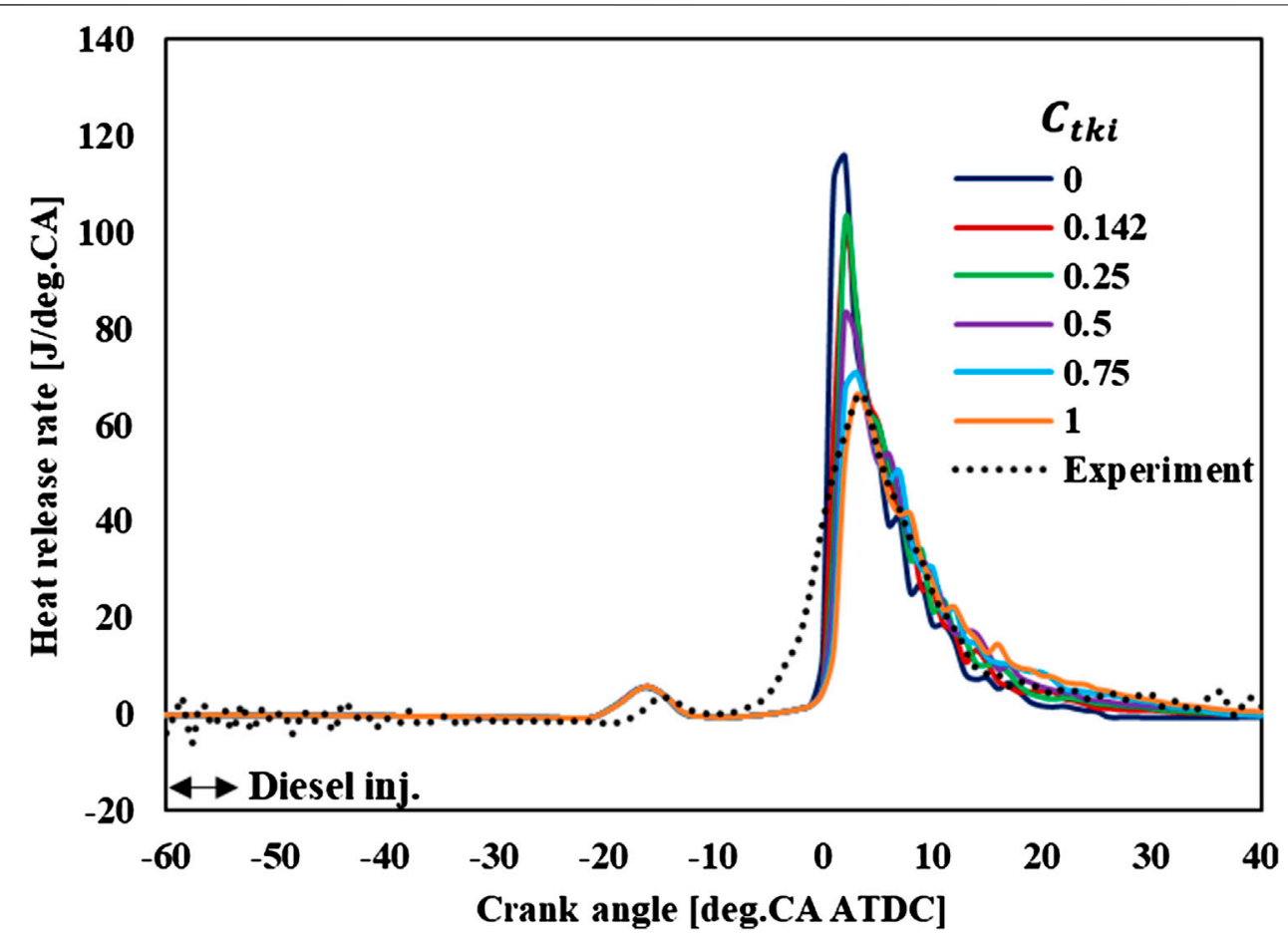

FIGURE 3 | Parametric study on the effect of $C_{t k i}$ parameter on the heat release prediction capacity of the model.

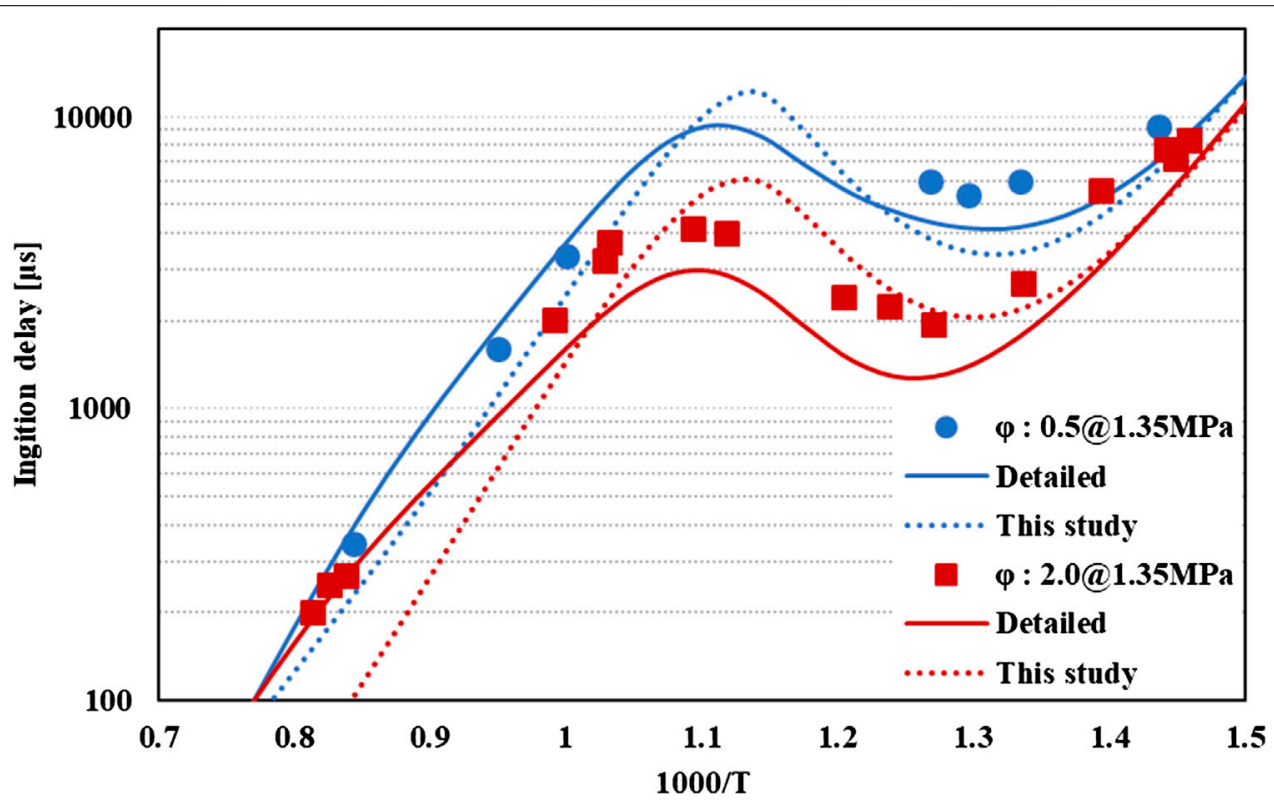

FIGURE 4 | Comparison of the ignition delay of n-heptane/air mixture in a shock-tube environment calculated by the reduced model of this study again the detailed model (Mehl and Curran, 2009) and experimental results (Ciezki and Adomeit, 1993).

The diesel physical properties were represented using an n-tetradecane model, while natural gas was represented by methane, which consists of almost $90 \%$ of its volume. The authors developed a new n-heptane/methane reduced model based on previous works (Patel et al., 2004; Mehl and Curran, 2009; Tsurushima, 2009) by adding reactions associated with species such as methane, methyl radical, acetylene and NOx formation. Details about the newly developed model with 47 


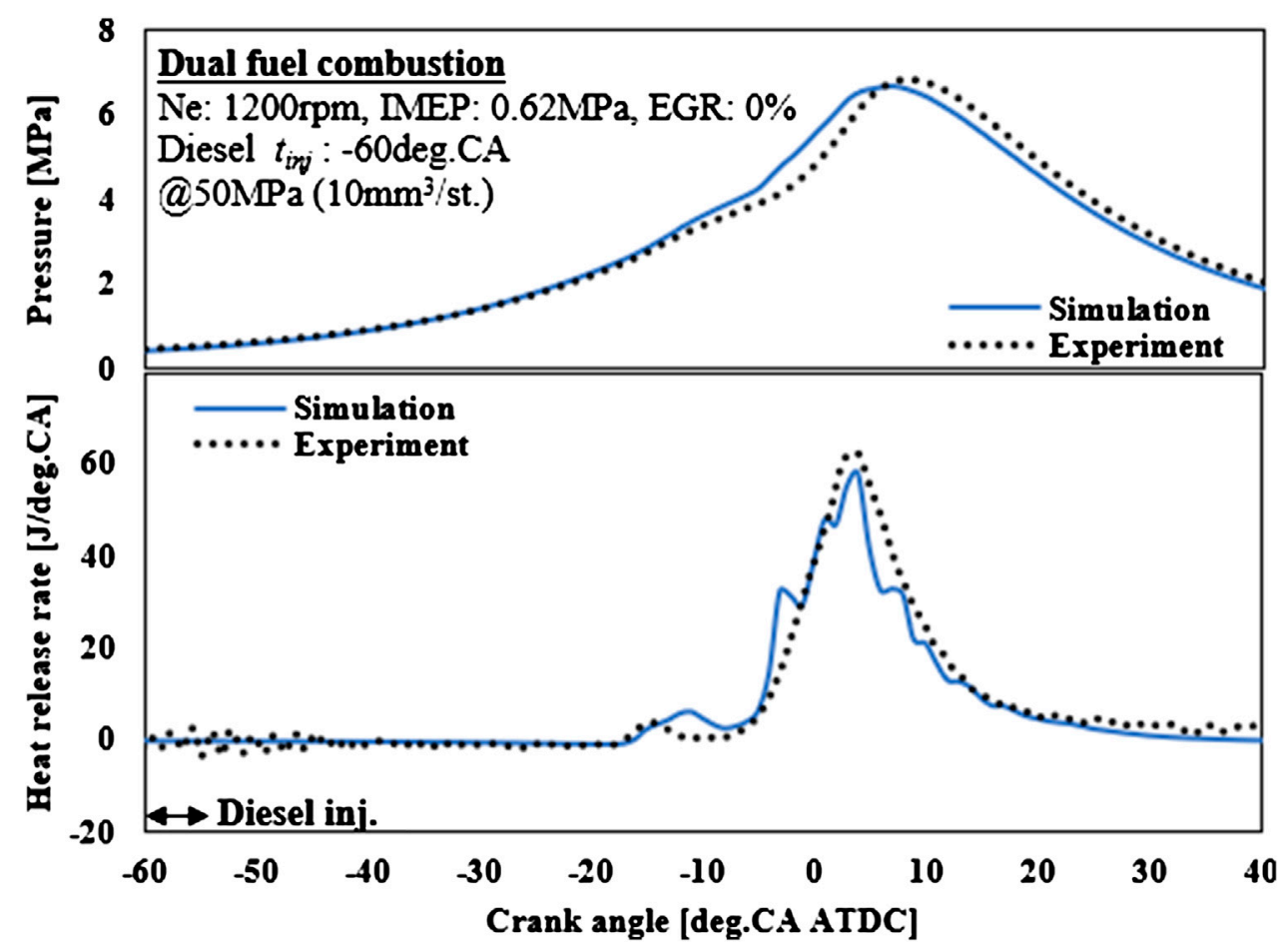

FIGURE 5 | Simulated in-cylinder pressure and heat release rate against experimental results for early diesel injection.

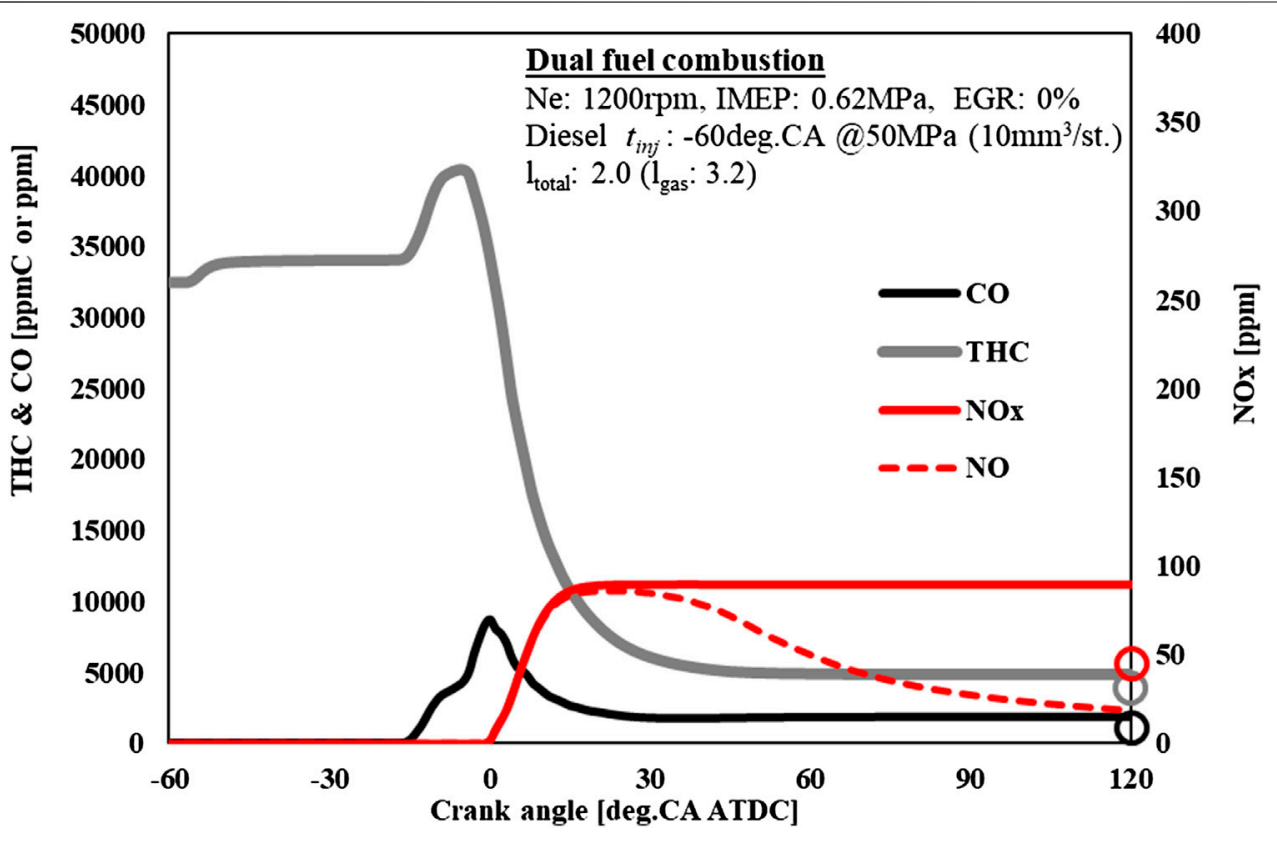

FIGURE 6 | Simulated emissions prediction (CO, THC, NOx, and NO) against experimental results (circles) for early diesel injection.

species and 87 reactions can found in (Tsujimura et al., 2012). The performance of the reduced model was compared to the detailed model by Mehl and Curran (2009) of 1,391 species and 5,935 reactions and experimental data obtained from Ciezki and Adomeit (1993). As presented in Figure 4, both models show similar characteristics with the reduced model slightly underpredicting 


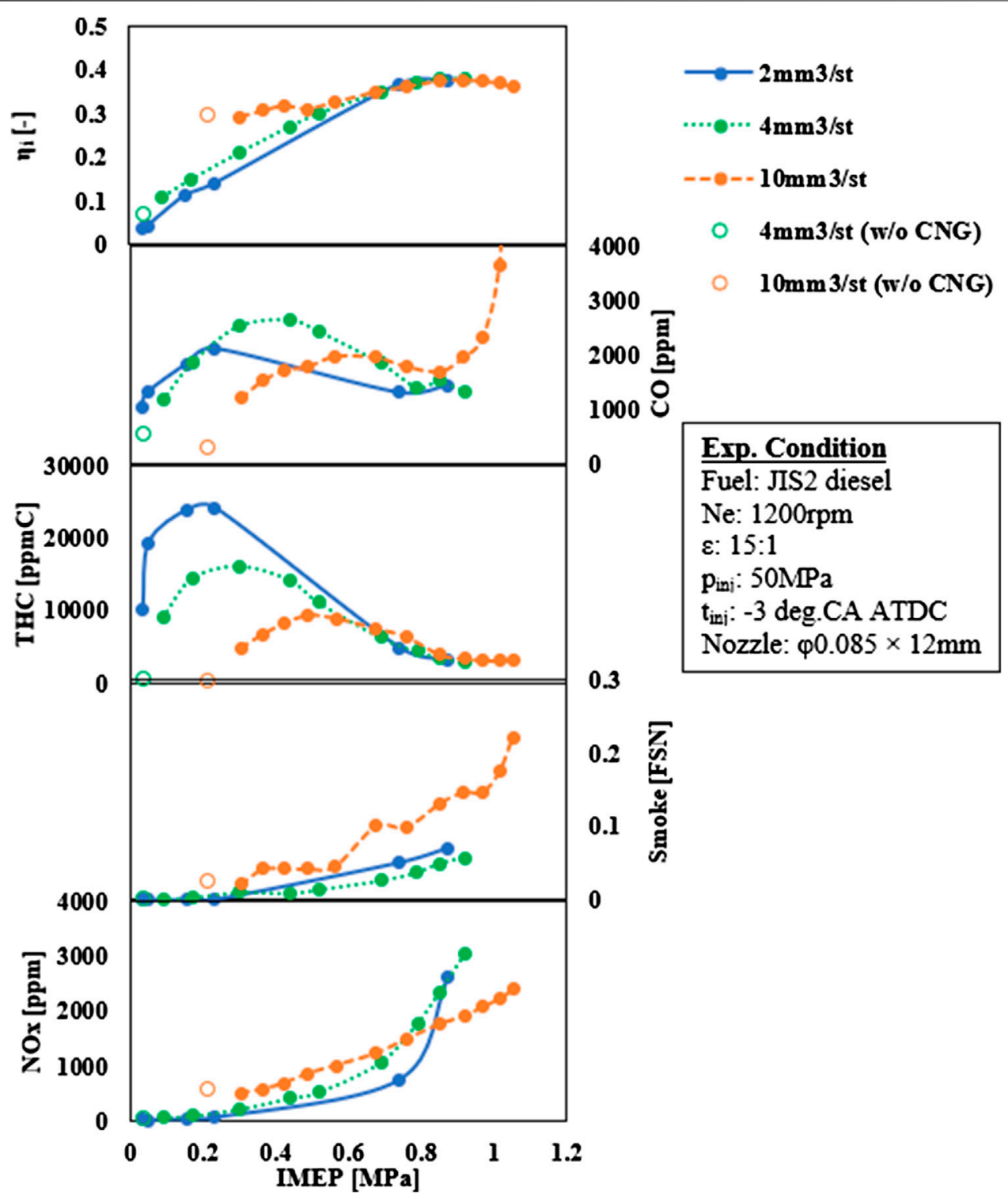

FIGURE 7 | Dual fuel engine performance characteristics under various IMEP and fuel ratios.

the ignition delay in high-temperature conditions. However, in the low-temperature region, both detailed and reduced models exhibit good agreement with the experimental data.

The reduced kinetic model was applied to the engine simulation case, and the results were compared to the data obtained from the experimental analysis in the engine set-up \#1. The model validation analysis presented in Figure $\mathbf{5}$ is for an early diesel injection at $-60^{\circ} \mathrm{CA}$ ATDC. The comparison chart shows a good agreement between the experimental and simulation results for both incylinder pressure and heat release rate. The model captures the onset of the low-temperature heat release, the slope, and the maximum level accurately. The simulated emission profiles, in Figure 6, also show a good agreement with the experimental data for most of the species except the NOx.

\section{RESULTS AND DISCUSSION}

All the experimental results presented in this manuscript were acquired in three engine set-ups providing a wide range of data acquisition with different engine geometry configurations and allowing direct visualization of the in-cylinder combustion events. Moreover, CFD simulation analysis was performed to obtain a deeper understanding of the combustion and emission formation phenomena.

\section{Baseline Operation}

The baseline performance of the natural gas-diesel dual-fuel engine was tested using the single-cylinder engine set-up \#1. Experimental tests were performed for pilot diesel injections of 2, 


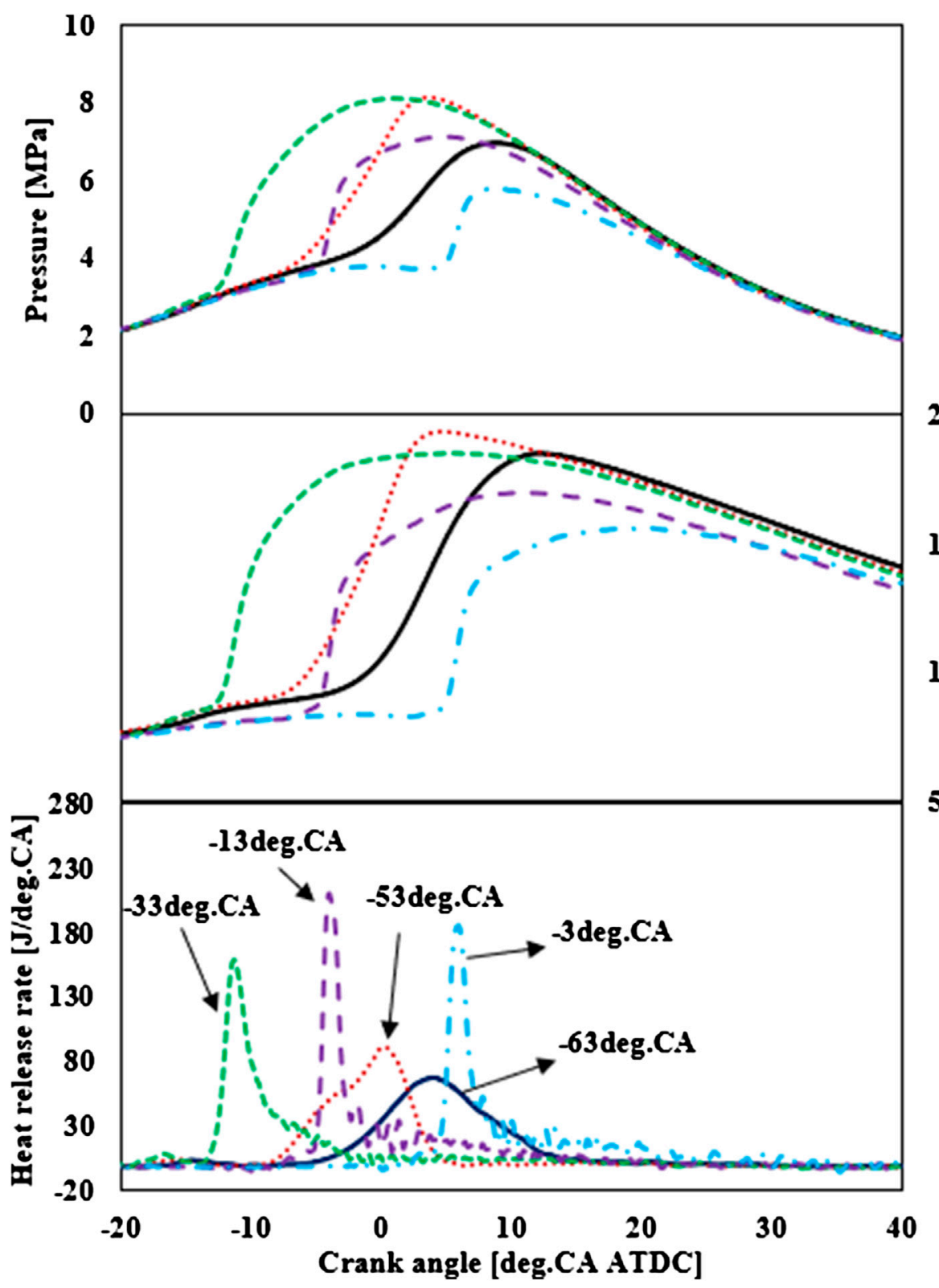

2000

500

FIGURE 8 | In-cylinder pressure, temperature, and rate of heat release rate for different diesel injection timings.

4 , and $10 \mathrm{~mm}^{3} / \mathrm{st}$ at $-3^{\circ} \mathrm{CA}$ ATDC, while the mass flow of the natural gas was varied to meet the targeted engine load.

Figure 7 shows the indicated thermal efficiency and emissions output behavior of the dual-fuel engine under different pilot injection amounts and indicated mean effective pressures. A strong correlation between the indicated efficiency and indicated mean effective pressure (IMEP) level is observed for all cases, with higher IMEP leading to maximum efficiency. The diesel amount has no significant effect in the high IMEP cases. However, when observing the low IMEP cases, it is evident that an increase in the pilot injection amount enhances the indicated thermal efficiency. From those mentioned above, it can be concluded that, at low engine loads, the lean natural gas pre- mixture conditions within the cylinder cannot guarantee a proper flame propagation when a small amount of diesel fuel is injected. At these conditions, the increase of the diesel/natural gas energy share ratio has a significant effect on the engine's combustion efficiency, which can be confirmed by the substantial drop in the number of THCs.

\section{Diesel Injection Strategies}

\section{Injection Timing}

The engine test results presented in the previous section were employing a fixed start of injection for diesel. In this section, the start of injection, for the engine set-up \# 1 , was varied from $-3^{\circ} \mathrm{CA}$ 


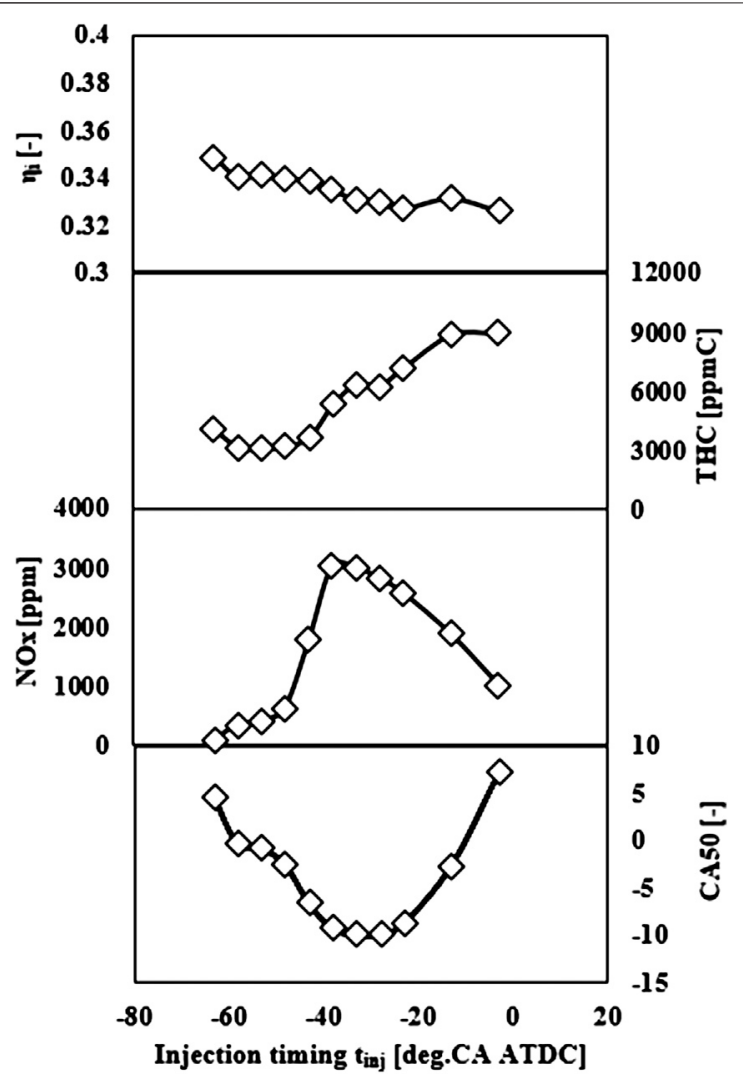

FIGURE 9 | Effect of diesel injection timing on indicated thermal efficiency, THC, NOx, and CA50 of the dual-fuel engine (experimental conditions as shown in Figure 8).

ATDC up to $-63^{\circ} \mathrm{CA}$ ATDC. Figure 8 shows the averaged incylinder pressure and heat release rate of dual-fuel combustion cases with the diesel injection timing set at $-3,-13,-33,53$, and $-63^{\circ} \mathrm{CA}$ ATDC.

It is clear from Figure 8 that as the diesel injection timing advanced from $-3^{\circ} \mathrm{CA}$ ATDC, the start of combustion also advanced. The onset of heat release for the $-13^{\circ} \mathrm{CA}$ case takes place a few degrees CA before the TDC featuring a steep increase and reaching the maximum heat release level among all the cases. The $-33^{\circ} \mathrm{CA}$ case showed an earlier start of combustion before the piston reaches the TDC and hence a milder heat release rate. When the start of injection was advanced to -53 and $-63^{\circ} \mathrm{CA}$, the start of combustion was delayed, with both cases showing a milder rate of heat release. Remarkably, this change of behavior can be seen in the NOx emissions chart presented in Figure 9. The NOx emission levels increase as the diesel injection timing advances from -3 to $-33^{\circ} \mathrm{CA}$. However, when the injection timing is further advanced, the NOx emissions drop with the earlier the injection giving lower NOx levels. The NOx behavior can be justified by observing the CA50 chart, which presents the piston location where $50 \%$ of the combustion occurred. The chart shows that the $-13^{\circ} \mathrm{CA}$ case exhibits the earliest CA50 value before the piston reaches the top dead center due to the steep heat release behavior. For the rest of the cases,
CA50 values closer to the TDC contribute to the reduction of the in-cylinder combustion temperature and hence NOx formation.

Furthermore, the injection timing shows a significant effect on the indicated thermal efficiency of the engine with earlier injections leading to increased efficiency. It is estimated that a late diesel injection reduces the ignition delay time, leading to a short diesel fuel dispersion period and hence limits the ability of igniting the lean natural gas mixture. On the other hand, an early diesel injection can provide enough time to homogenize the airfuel mixture and improve the engine's combustion efficiency, confirmed by the reduced number of THCs at the exhaust of the engine.

\section{Split Injection}

The previous section revealed that the diesel injection timing is an important parameter to control the operating efficiency and emissions formation of a natural gas-diesel dual-fuel engine. Dual-fuel engine operation at low-load exhibited high amounts of THCs at the exhaust of the engine, indicating a low combustion efficiency due to unburned fuel. To further optimize the ability of diesel fuel to ignite natural gas under lean conditions, a split diesel injection strategy was assessed and presented in this section.

For this analysis, the optically accessible engine set-up \#2 was preferred to visualize the in-cylinder combustion phenomena. For this type of engine, experiments can only be performed under cold-start conditions, which deteriorates the capacity of diesel fuel to ignite the lean natural gas-air mixture. For this reason, the No. 0 Solvent $M$ with a cetane number higher than that of diesel fuel was used in this experimental analysis.

Figure 10 compares the heat release rate and combustion events of two cases with (A) an early single injection of $10 \mathrm{~mm}^{3}$ at $-60^{\circ} \mathrm{CA}$ ATDC and (B) a split injection strategy of $5 \mathrm{~mm}^{3}$ per injection at $-40 \mathrm{CA}$ ATDC and the TDC of the engine.

As it can be observed from the in-cylinder images, for the early injection case, the combustion starts near the cylinder wall and the squish area and spreads towards the center of the cylinder. The numerical analysis images shown in Figure 11 can confirm that in case (A), combustion started from the squish area, where a high-temperature level exists at the TDC and spreads towards the central axis of the combustion chamber. The premixed combustion case exhibits low-intensity flames that cover a wide area of the cylinder chamber with the generated NOx emission measured at the exhaust pipe being as low as $45 \mathrm{ppm}$.

On the other hand, for the split injection case, no combustion can be observed before the start of the second diesel injection. Once the second injection occurs, luminous diffusion flames can be seen near the cylinder wall causing the steep increase shown in the heat release diagram. The computational analysis in Figure 11 illustrates that for the split injection case, case (B), the start of combustion was within the main area of the combustion chamber. The case exhibits much higher generated temperatures due to the second late injection leading to local fuel-rich regions within the combustion chamber. As a results, the NOx formation for the split injection case is over 15 times higher that the early injection case, with the experimental data reaching a reading of $758 \mathrm{ppm}$ at the exhaust side of the engine. 

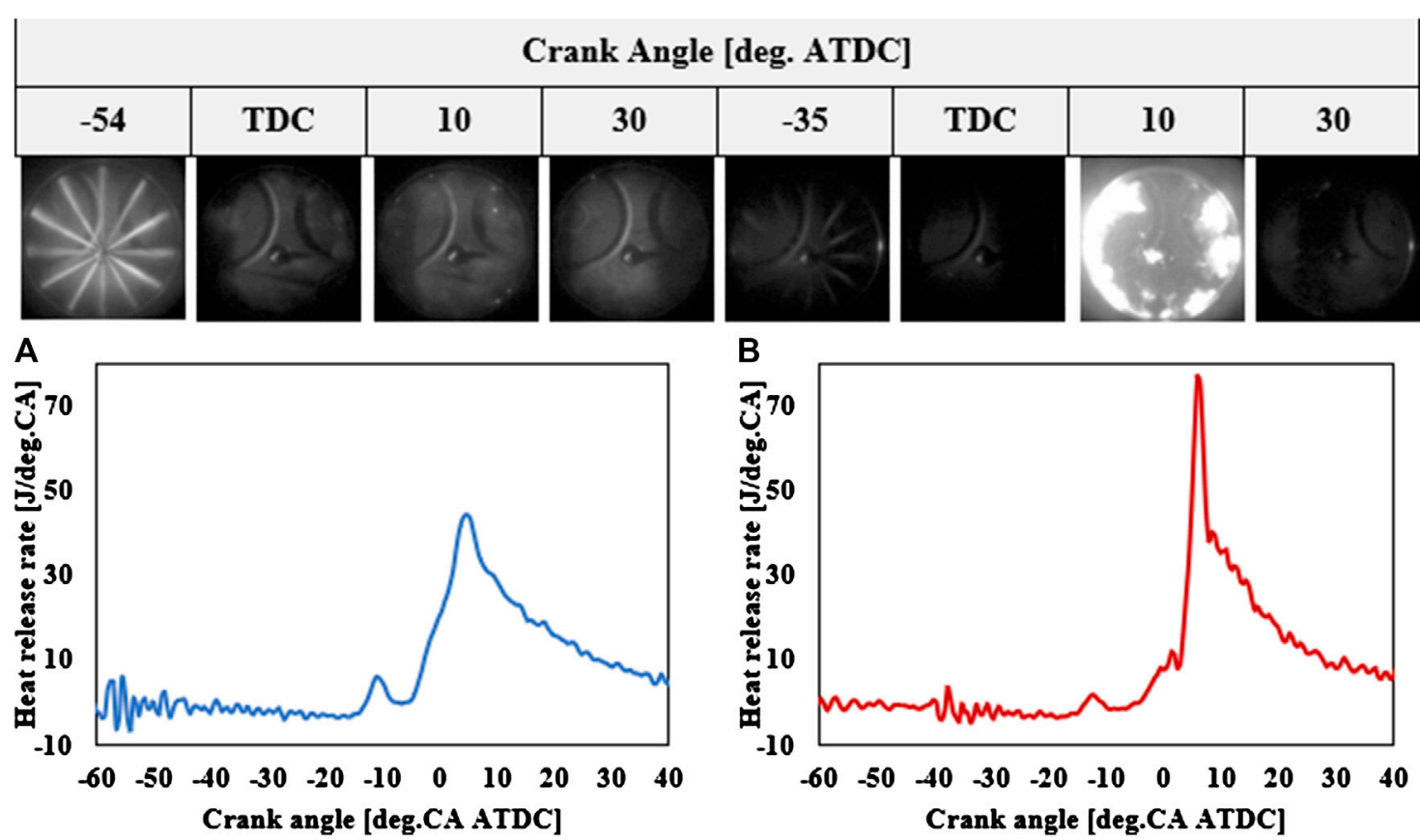

FIGURE 10|Rate of heat realease and in-cylinder images for $\mathbf{( A )}$ early fuel inejction case (IMEP $\left.=0.62 \mathrm{MPa}, t_{\text {inj }}=-60^{\circ} \mathrm{ATDC}, \mathbf{Q}_{d}=10 \mathrm{~mm}{ }^{3} / \mathrm{cycle}\right)$, (B) split injection case (IMEP $=0.60 \mathrm{MPa}, t_{\mathrm{inj}}=-40^{\circ} \mathrm{ATDC}$ and TDC, $Q_{d}=5$ and $5 \mathrm{~mm}^{3} /$ cycle).

\begin{tabular}{|c|c|c|c|}
\hline \multicolumn{4}{|c|}{ Crank angle [deg.CA ATDC] } \\
\hline-5 & TDC & 10 & 30 \\
\hline
\end{tabular}

A
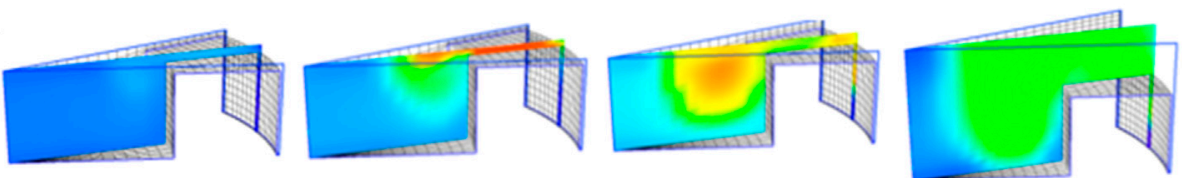

B
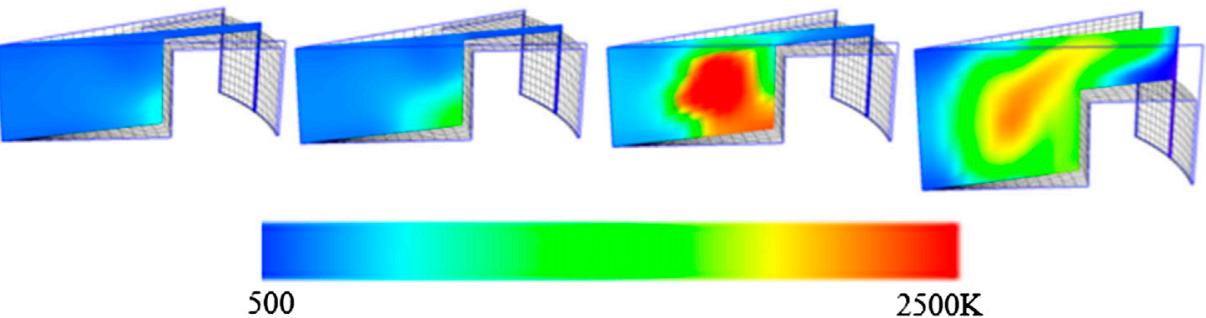

FIGURE 11 | In-cylinder temperature surface plots for (A) early fuel inejction case (IMEP $\left.=0.62 \mathrm{MPa}, t_{\text {inj }}=-60^{\circ} \mathrm{ATDC}, Q_{d}=10 \mathrm{~mm}^{3} / \mathrm{cycle}\right)$, (B) split injection case $\left(\mathrm{IMEP}=0.60 \mathrm{MPa}, t_{\text {inj }}=-40^{\circ} \mathrm{ATDC}\right.$ and TDC, $Q_{d}=5$ and $5 \mathrm{~mm}^{3} /$ cycle) .

Figure 12 presents the heat release of the two cases against the main species profiles. A decrease in the $\mathrm{C}_{7} \mathrm{H}_{16}$ coincides with the onset of the low-temperature heat release for both cases. It can be calculated that over $2 / 3$ of the $\mathrm{C}_{7} \mathrm{H}_{16}$ for case $(\mathrm{A})$, and the vast majority of the $\mathrm{C}_{7} \mathrm{H}_{16}$ from the first injection for case (B) react before the start of the high-temperature heat release zone. On the other hand, the $\mathrm{CH}_{4}$ profiles for both cases remain unchanged until the start of the high-temperature heat release zone. Case (A) exhibits an improved $\mathrm{CH}_{4}$ combustion efficiency, which is a result of the homogeneous diesel/CNG mixture covering a more extensive combustion area. A comparison over the unburned hydrocarbons and $\mathrm{CH}_{4}$ profiles shows that $89 \%$ of the UHC is a source of $\mathrm{CH}_{4}$ for case (A), while this ratio increases to $96 \%$ for case (B). Finally, the onset of the CO formation for both cases 

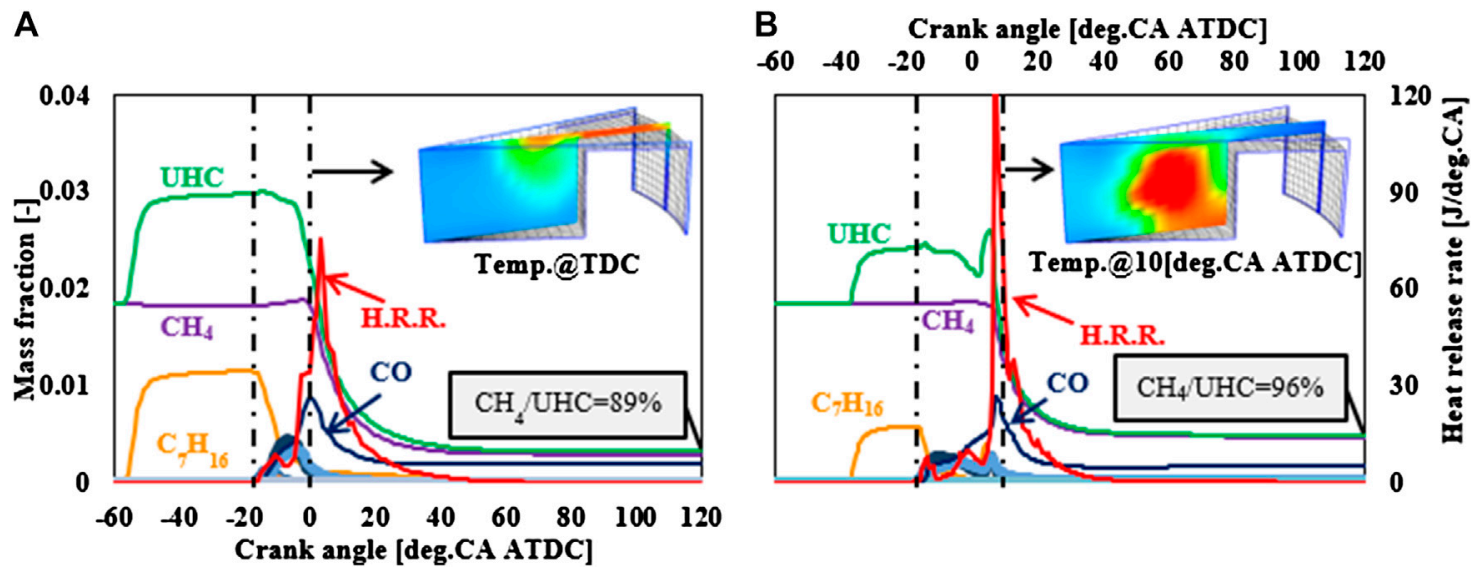

FIGURE 12 | Main species and heat release rate profiles for (A) early fuel injection case (IMEP=0.62MPa, tinj=-60deg.ATDC, Qd=10mm3/cycle), (B) split injection case (IMEP=0.60MPa, tinj=-40deg.ATDC \& TDC, Qd=5 \& 5mm3/cycle).

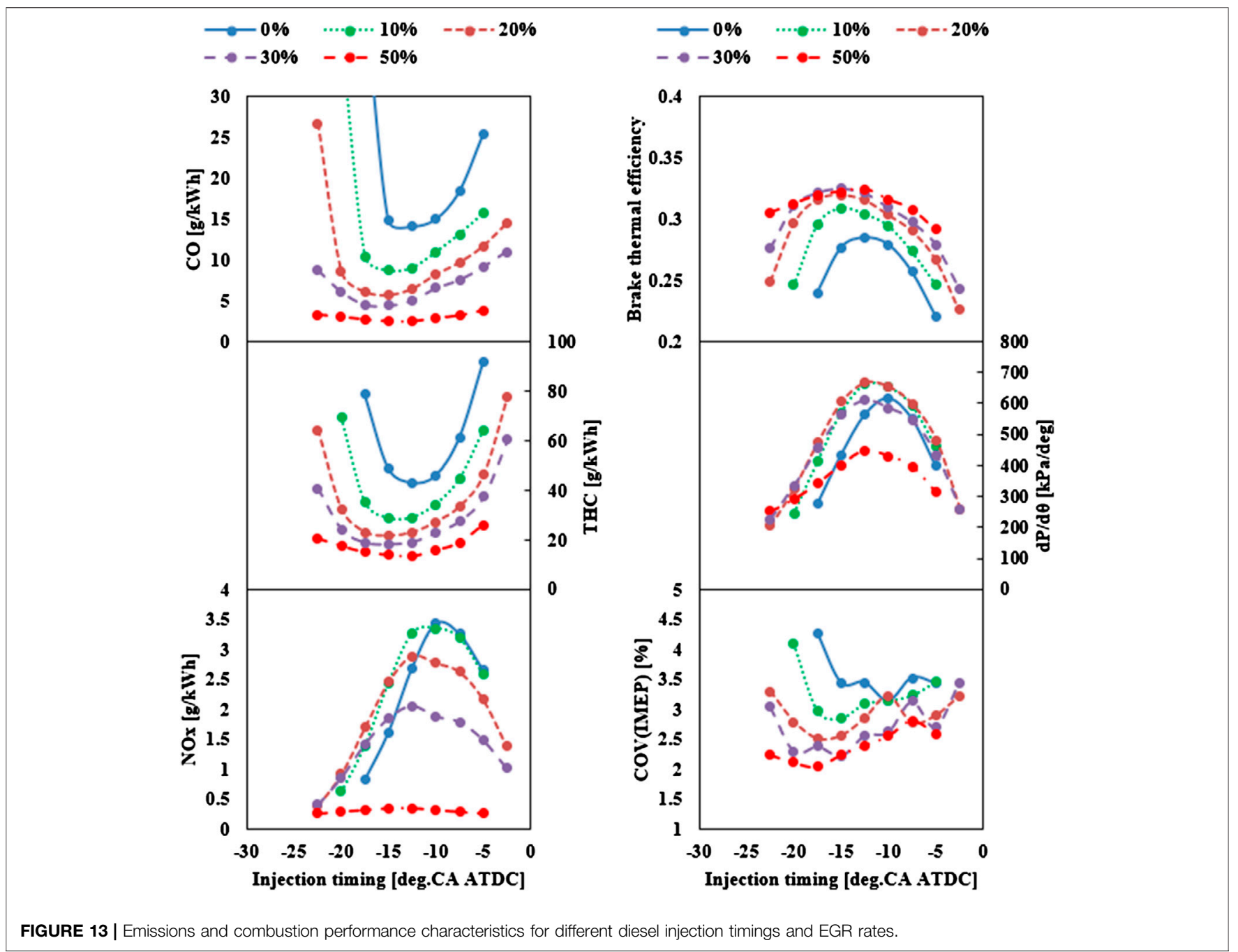



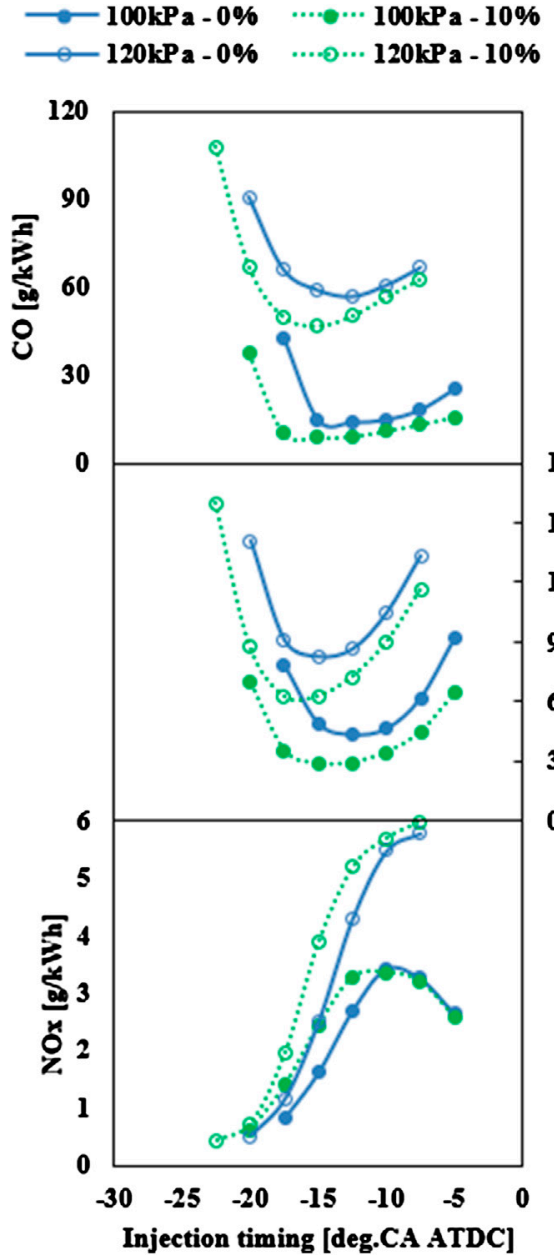

$\longrightarrow 100 \mathrm{kPa}-0 \% \quad \cdots \cdots 100 \mathrm{kPa}-10 \%$

$120 \mathrm{kPa}-0 \% \quad \cdots, \cdots 120 \mathrm{kPa}-10 \%$

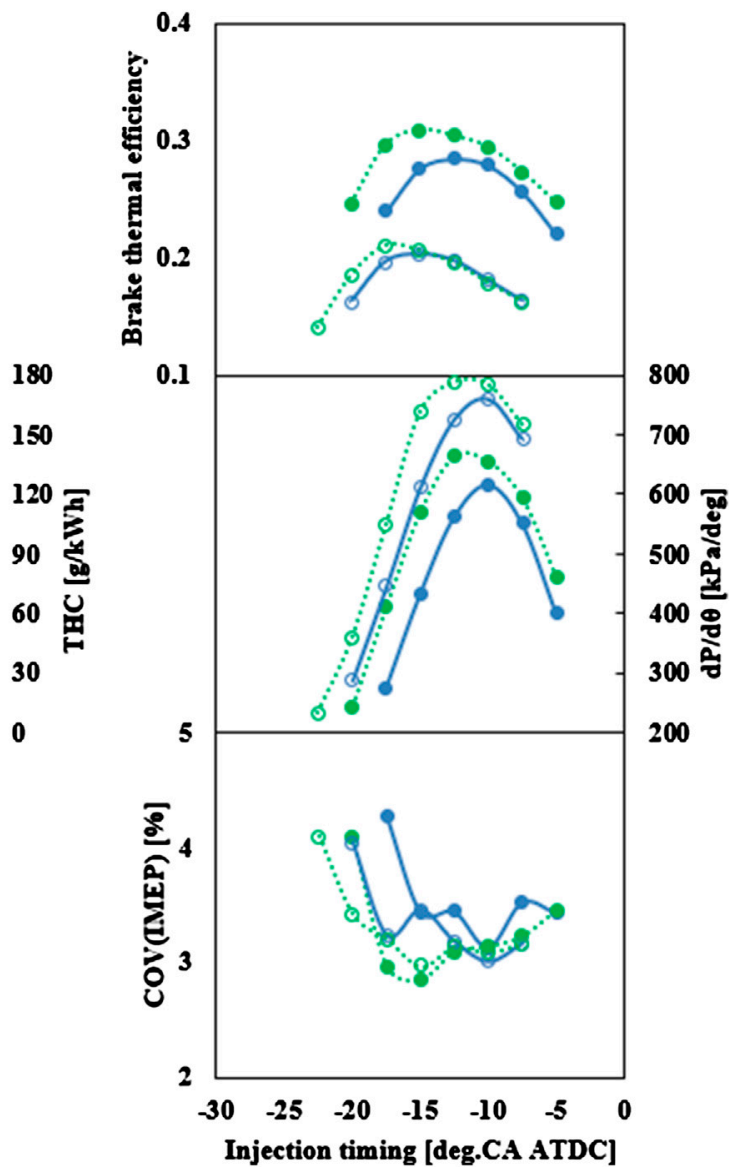

FIGURE 14 | Emissions and combustion performance characteristics for different diesel injection timings, intake pressure, and EGR rates.

indicates that the low temperature heat release (LTHR) of $\mathrm{C}_{7} \mathrm{H}_{16}$ forms the $\mathrm{CO}$ emissions. The $\mathrm{CO}$ formation for case (B) is more significant due to the second diesel injection creating local fuelrich areas within the cylinder.

\section{Air-Path Strategies}

The effects of different air-path strategies on the efficiency and emissions formation of the natural gas-diesel dual-fuel engine have been investigated and reported in this section. Two different strategies, i.e., EGR and intake boosting, have been tested for an engine speed of 1,200 rpm. For this set of experiments, the multicylinder engine set-up \#3 was chosen to allow operation with a turbocharger and a high-pressure Hot-EGR system. The experimental procedure focused on the low-load engine zone, of $0.3 \mathrm{MPa}$ brake mean effective pressure (BMEP) with a CNGdiesel ratio of 76:24, where high unburned gas emissions are observed.

\section{Exhaust Gas Recirculation}

The experimental analysis was performed for engine operation with EGR rates of up to 50\%, and the diesel injection timing ranged from $-30^{\circ} \mathrm{CA}$ ATD to TDC. The $50 \%$ EGR rate was set as the maximum limit as any operation with higher EGR rates led to unstable combustion operation with lower thermal efficiency. Figure 13 compares the emission formation and engine performance for different EGR rates and diesel injection timings. As the EGR rate increases to $40 \%$, the CO and THC are significantly reduced, leading to high combustion and BTE. The introduction of Hot-EGR, which bypasses the EGR cooler, leads to a significant increase of the intake charge temperature in the range of $10-90^{\circ} \mathrm{C}$ and promotes oxidation. Moreover, the injection timing plays a vital role in the combustion performance, $\mathrm{CO}$ and THC output of the engine with cases with an injection angle at -17.5 to $-12.5^{\circ} \mathrm{CA}$ ATCD showing the lowest emissions.

A further increase of EGR rate $(50 \%)$ did not provide any significant improvements to the $\mathrm{CO}$ and THC emissions. On the other hand, a small increase was observed for cases with an early diesel injection, which indicates that low oxygen rates within the cylinder could deteriorate the oxidation process. However, a $50 \%$ EGR rate contributes to a significant NOx reduction, while this level of EGR reduced the effect of injection timing on the NOx formation. Moreover, a high EGR rate was found to contribute 
significantly to the reduction of the $\mathrm{dP} / \mathrm{d} \theta$ and coefficient of variance $(\mathrm{COV})$ of the engine.

\section{Intake Boosting}

The effect of intake boosting at the low-load range of the engine for operation with and without EGR was experimentally tested. High rates of EGR were challenging to be achieved for the boosted case of $120 \mathrm{kPa}$ intake pressure, and therefore the EGR rate was limited to $10 \%$. The tendency of the boosted cases for the emissions output data is alike the non-boosted cases presented earlier. However, for the boosted cases, all the emissions significantly increase, particularly at the early diesel injection region. The COV of IMEP chart indicates that the COV for the boosted and non-boosted cases does not significantly increase, therefore the emissions increase is not due to combustion cycles fluctuations. It is estimated that the increase in $\mathrm{CO}$ and THC and the BTE reduction is a result of the excessive lean CNG-air mixture. Therefore, it can be concluded that boosting at a low-load operation level is not an appropriate strategy to optimize the combustion efficiency of the CNG-diesel dual duel engine. On the other hand, the throttling of the engine to reduce the intake pressure could potentially improve the emissions output, but this could harm the COV of IMEP rates.

\section{CONCLUSIONS}

The paper presents experimental and simulation studies on natural gas-diesel dual-fuel combustion. The research work was carried out on three different engine set-ups of single cylinder with and without optical access and multi-cylinder characteristics. CFD simulations with a developed wellcorrelated skeletal model were performed to gain a deeper understanding of the combustion phenomena. The analysis focused on the effect of diesel injection timing, quantity, and pattern as well as different airpath strategies, such as EGR and boosting, on the combustion and emissions performance of the dual-fuel engine, with a focus on the low-load region.

\section{REFERENCES}

Abani, N., and Reitz, R. D. (2007). Unsteady turbulent round jets and vortex motion. Phys. Fluids. 19 (12), 125102. doi:10.1063/1.2821910

Abdelaal, M. M., and Hegab, A. H. (2012). Combustion and emission characteristics of a natural gas-fueled diesel engine with EGR. Energy Convers. Manag. 64, 301-312. doi:10.1016/j.enconman.2012.05.021

Amsden, A. (1997). LA Report, LA-13313-MS. KIVA-3V: a block-structured KIVA program for engines with vertical or canted valves. doi:10.1016/0375-6505(82) 90028-1

ANSYS, Inc. (2019). ANSYS 2019R1 Forte best practises. Canonsburg, PA:ANSYS Inc.

Cheenkachorn, K., Poompipatpong, C., and Ho, C. G. (2013). Performance and emissions of a heavy-duty diesel engine fuelled with diesel and LNG (liquid natural gas). Energy 53, 52-57. doi:10.1016/j.energy.2013.02.027

Ciezki, H. K., and Adomeit, G. (1993). Shock-tube investigation of self-ignition of $\mathrm{N}$-heptane-air mixtures under engine relevant conditions. Combust. Flame. 93 (4), 421-433. doi:10.1016/0010-2180(93)90142-p
The results showed that an advanced diesel injection could significantly reduce the NOx formation and enhance the engine's thermal efficiency. The CFD study revealed that the unburned hydrocarbon emissions at low loads mostly result from unburned methane. A split diesel injection strategy did not provide any benefits on the emissions formation, and it further deteriorated the THCs by increasing the unburned $\mathrm{CH}_{4}$. Hot EGR contributed significantly to the simultaneous reduction of NOx and unburned species while it increased the thermal efficiency of the engine at low-load operation. On the other hand, intake boosting did not provide any performance or emission benefits as it increased the unburned emission components and deteriorated the thermal efficiency of the engine.

\section{DATA AVAILABILITY STATEMENT}

The raw data supporting the conclusions of this article will be made available by the authors, without undue reservation.

\section{AUTHOR CONTRIBUTIONS}

PD analyzed the data and wrote the manuscript with the support of TT and HK. TT managed the project and developed the reaction mechanism used in the simulation study. HK was responsible for the multi-cylinder engine testing. KA. performed the experimental analysis on the single-cylinder engines. NK planned the project and designed the diesel injectors used in the study. YN managed the project and contributed to experimental studies.

\section{FUNDING}

The authors declare that part of the research was supported by DENSO CORPORATION.

Dimitriou, P., and Javaid, R. (2020). A review of ammonia as a compression ignition engine fuel. Int. J. Hydrog. Energy. 45, 7098-7118. doi:10.1016/j. ijhydene.2019.12.209.

Dimitriou, P., and Tsujimura, T. (2017). A review of hydrogen as a compression ignition engine fuel. Int. J. Hydrog. Energy. 42 (38), 24470-24486. doi:10.1016/j. ijhydene.2017.07.232

IRENA (2019). Hydrogen: a renewable energy Perspective.Tokyo, Japan: IRENA. ISO 10054 (1998). Internal combustion compression ignition engines-apparatus for measurement of smoke from diesel engines operating under steady state conditions-Filter type smoke meter. Berlin: Beuth Verlag.

Karim, G. A. (2003). Combustion in gas fueled compression: ignition engines of the dual fuel type. J. Eng. Gas Turbines Power. 125 (3), 827-836. doi:10.1115/1.1581894

Kojima, H., Yoshida, A., Tsujimura, T., Fujino, T., Kawakita, S., Kondo, W., et al. (2016). A strategy of intake gas control for diesel dual fuel engine with natural gas and diesel fuel. Trans. Soc. Automot. Eng. Jpn. Inc. 47 (4), 889-894. doi:10. 11351 /jsaeronbun.47.889

Kong, S.-C., and Reitz, R. D. (2002). Use of detailed chemical kinetics to study HCCI engine combustion with consideration of turbulent mixing effects. J. Eng. Gas Turbines Power. 124 (3), 702-707. doi:10.1115/1.1413766 
Kusaka, J., Daisho, Y., Kihara, R., Saito, T., and Nakayama, S. (1998). “Combustion and exhaust gas emissions characteristics of a diesel engine dual-fueled with natural gas," in Fourth international symposium COMODIA. Kyoto, Japan, July 20-23, 1998

Liang, L., Naik, C. V., Puduppakkam, K., Wang, C., Modak, A., Meeks, E., et al. (2010). Efficient simulation of diesel engine combustion using realistic chemical kinetics in CFD. SAE Technical papers. doi:10.4271/2010-01-0178

Liu, J., Yang, F., Wang, H., Ouyang, M., and Hao, S. (2013). Effects of pilot fuel quantity on the emissions characteristics of a CNG/diesel dual fuel engine with optimized pilot injection timing. Appl. Energy. 110, 201-206. doi:10.1016/j. apenergy.2013.03.024

Lounici, M. S., Loubar, K., Tarabet, L., Balistrou, M., Niculescu, D.-C., and Tazerout, M. (2014). Towards improvement of natural gas-diesel dual fuel mode: an experimental investigation on performance and exhaust emissions. Energy 64: 200-211. doi:10.1016/j.energy.2013.10.091

Maricq, M. M., Chase, R. E., Xu, N., and Laing, P. M. (2002). The effects of the catalytic converter and fuel sulfur level on motor vehicle particulate matter emissions: light duty diesel vehicles. Environ. Sci. Technol. 36 (2), 283-289. doi:10.1021/es010962l

Mehl, M., and Curran, H. J. (2009). "Chemical kinetic modeling of component mixtures relevant to gasoline." in European combustion meeting, 1-6. Vienna, Austria, March 2, 2009

Papagiannakis, R. G., Rakopoulos, C. D., Hountalas, D. T., and Rakopoulos, D. C. (2010). Emission characteristics of high speed, dual fuel, compression ignition engine operating in a wide range of natural gas/diesel fuel proportions. Fuel 89 (7), 1397-1406. doi:10.1016/j.fuel.2009.11.001

Patel, A., Song, C., and Reitz, R. D. (2004). Development and validation of a reduced reaction mechanism for HCCI engine simulations. SAE Technical papers. doi:10.4271/2004-01-0558.

Paul, A., Bose, P. K., Panua, R. S., and Banerjee, R. (2013). An experimental investigation of performance-emission trade off of a CI engine fueled by dieselcompressed natural gas $(\mathrm{CNG})$ combination and diesel-ethanol blends with CNG enrichment. Energy 55, 787-802. doi:10.1016/j.energy.2013.04.002

Reitz, R. D., and Beale, J. C. (1999). Modeling spray atomization with the Kelvin-Helmholtz/Rayleigh-Taylor Hybrid model. Atom. Spr. 9 (6), 623-650. doi:10.1615/atomizspr.v9.i6.40

Sahoo, B. B., Sahoo, N., and Saha, U. K. (2009). Effect of engine parameters and type of gaseous fuel on the performance of dual-fuel gas diesel engines-a critical review. Renew. Sustain. Energy Rev. 13 (6-7), 1151-1184. doi:10.1016/j.rser.2008.08.003

Selim, M. Y. E. (2001). Pressure-time characteristics in diesel engine fueled with natural gas. Renew. Energy. 22 (4), 473-489. doi:10.1016/s0960-1481(00)00115-4
Shenghua, L., Longbao, Z., Ziyan, W., and Jiang, R. (2003). Combustion characteristics of compressed natural gas/diesel dual-fuel turbocharged compressed ignition engine. Proc. Inst. Mech. Eng. Part D J. Automob. Eng. 217, 833-838. doi:10.1177/095440700321700909

Srinivasan, K. K., Krishnan, S. R., and Midkiff, K. C. (2006). Improving low load combustion, stability, and emissions in pilot-Ignited natural gas engines. Proc. Inst. Mech. Eng. Part D J. Automob. Eng. 220 (2), 229-239. doi:10.1243/ 09544070jauto104

Tsujimura, T., Aoyagi, K., Kurimoto, N., and Nishijima, Y. (2012). “Combustion analysis for natural gas/diesel dual fuel engine," in Proceedings of the 8th international conference on modeling and diagnostics for advanced engine systems, Fukuoka, Japan, July 23-26, 2012 COMODIA 2012, 380-385.

Tsurushima, T. (2009). A new skeletal PRF kinetic model for HCCI combustion. Proc. Combust. Inst. 32 (2), 2835-2841. doi:10.1016/j.proci.2008.06.018

UNFCC (2015). “Adoption of the Paris agreement," in Conference of the parties on its twenty-first session. Paris, France, November 30-December 12, 2015

Wang, Y., Ge, H.-W., and Reitz, R. D. (2010). Validation of mesh- and timestepindependent spray models for multi-dimensional engine CFD simulation. SAE Int. J. Fuels Lubr. 3, 277-302. doi:10.4271/2010-01-0626

Wei, L., and Geng, P. (2016). A review on natural gas/diesel dual fuel combustion, emissions and performance. Fuel Process. Technol. 142, 264-278. doi:10.1016/j. fuproc.2015.09.018

Yang, B., Xi, C., Wei, X., Zeng, K., and Lai, M.-C. (2015). Parametric investigation of natural gas port injection and diesel pilot injection on the combustion and emissions of a turbocharged common rail dual-fuel engine at low load. Appl. Energy. 143, 130-137. doi:10.1016/j.apenergy.2015.01.037

Conflict of Interest: Authors KA, NK, and YN were employed by the company DENSO CORPORATION, who was also a funder of this study. The funder had the following involvement with the study: Involved in the experimental analysis, project design, and management.

Copyright (c) 2020 Dimitriou, Tsujimura, Kojima, Aoyagi, Kurimoto and Nishijima. This is an open-access article distributed under the terms of the Creative Commons Attribution License (CC BY). The use, distribution or reproduction in other forums is permitted, provided the original author(s) and the copyright owner(s) are credited and that the original publication in this journal is cited, in accordance with accepted academic practice. No use, distribution or reproduction is permitted which does not comply with these terms. 